See Article page 13 .

\section{Commentary: Where does your distal aortic anastomosis lead to?}

\author{
Ari A. Mennander, MD, PhD
}

Patients favor one-stage surgery without complications and fear of reoperation; however, the thoracic aorta is a dynamic vessel that is part of the patient's overall condition and is vastly dependent on systematic and connective tissue disorders. Substantial evidence shows that the outcome after aortic surgery depends on different aortopathy, ${ }^{1-3}$ and preparedness for a second-stage operation is recommendable.

In this issue of the Journal, Neri and colleagues ${ }^{4}$ share their surgical experience of 146 patients with various thoracic aortic diseases, including degenerative aneurysms in 91 patients and chronic or acute aortic dissections in 55 patients; 45 cases represent reoperations, and 14 encompass connective tissue disorders. Astutely, in this very heterogeneous cohort of patients, the authors propose the use of a practical collared elephant trunk prosthesis to ensure blood circulation of the aorta beyond the aortic arch. The described collared aortic prosthesis may facilitate surgery of the distal anastomosis while avoiding temporary invagination of the proximal part of the graft inside the floppy distal part of the graft is avoided. The prosthesis allows for a tailored second-stage operation whenever the distal part of the aorta needs further attention. Technical tips are generously offered, including the strategy for aortic fenestration, performance of surgery in a sequenced fashion, and use of mediastinal sponge packing in patients with persistent bleeding.

The strategy includes vigilant surveillance after surgery. After surgery, 16 patients died before 30 days, 8 sustained

From Tampere University Heart Hospital and Tampere University, Tampere, Finland. Disclosures: The author reported no conflicts of interest.

The Journal policy requires editors and reviewers to disclose conflicts of interest and to decline handling or reviewing manuscripts for which they may have a conflict of interest. The editors and reviewers of this article have no conflicts of interest.

Received for publication Dec 5, 2020; revisions received Dec 5, 2020; accepted for publication Dec 18, 2020; available ahead of print Dec 25, 2020.

Address for reprints: Ari A. Mennander, MD, PhD, Tampere University Heart Hospital, SDSKIR, PL 2000, Tampere, Finland (E-mail: ari.mennander@sydansairaala. fi).

JTCVS Techniques 2021;6:30-1

2666-2507

Copyright (C) 2020 The Authors. Published by Elsevier Inc. on behalf of The American Association for Thoracic Surgery. This is an open access article under the CC BY-NCND license (http://creativecommons.org/licenses/by-nc-nd/4.0/).

https://doi.org/10.1016/j.xjtc.2020.12.016

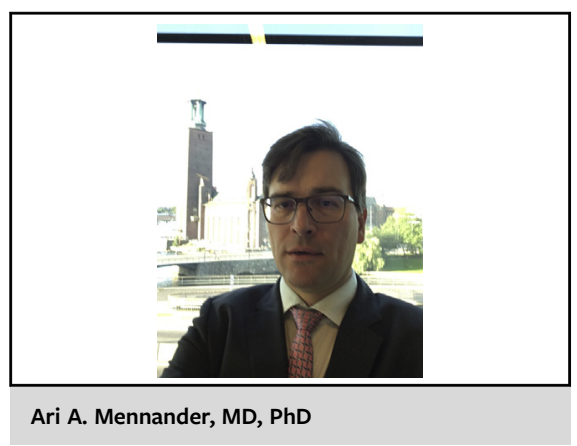

CENTRAL MESSAGE

The possibility of a second-stage

intervention challenges the

choice of technical strategy dur-

ing aortic surgery.

stroke, and 1 had paraplegia. As expected, 113 patients underwent a second-stage procedure, including 97 with endovascular grafting; after the subsequent grafting, 6 additional patients died within 30 days, 12 patients had paraplegia, and 9 patients had delayed paraplegia. Freedom from further treatment was $87 \%$ at 5 years.

The authors summarize a single institutional experience using the collared prosthesis with a relatively small number of patients. Surgery was considered if the maximum diameter of the thoracic aorta exceeded $60 \mathrm{~mm}$ in asymptomatic patients. The study proposes a universal strategy for many different aortic pathologies, including connective tissue disorders such as Marfan syndrome, chronic dissection, and degenerative aortic aneurysms, and for different locations of the primary disease. The overall patient outcome may depend on the time gap between the first and second operations. Although only a few cases of acute dissection are included, most of the emergencies were operated on differently during the same period of analysis.

It would be interesting to study the described surgical strategy and learn from the patient outcomes in homogenous patient groups. What are the possible advantages of using the traditional floppy elephant trunk with or without the collar instead of a popular frozen hybrid prosthesis? The floppy elephant trunk part of the prosthesis might not sufficiently cover all tears of the dissecting aorta, although it may be practical for extremely wide aortas; however, the frozen hybrid prosthesis also may need subsequent retrograde intervention, and delayed paraplegia still may be related to the length of the distal potion of any aortic graft. In elective cases, the decision for the initial prosthesis may 
include pondering different technical features of a plausible second-stage operation.

\section{References}

1. Kreibich M, Ryslki B, Czerny M, Pingpoh C, Siepe M, Beyersdorf F, et al. Type A aortic dissection in patients with bicuspid aortic valve aortopathy. Ann Thorac Surg. 2020;109:94-100.
2. Braverman AC, Moon MR, Geraghty P, Willing M, Bach C, Kouchoukos NT. Pregnancy after aortic root replacement in Loeys-Dietz syndrome: high risk of aortic dissection. Am J Med Genet A. 2016;170:2177-80.

3. Li N, Zhang Y, Gao Y, Bai Y, Qiao F, Tan M, et al. Long-term outcomes of surgical procedures for Marfan syndrome: aortic dissection versus aneurysm. J Thorac Dis. 2020;12:249-57.

4. Neri E, Muzzi L, Tucci E, Cini M, Barabesi L, Tommasino G, et al. Arch replacement with collared elephant trunks: the Siena approach. J Thorac Cardiovasc Surg Tech. 2021;6:13-27. 